\title{
The Corporate Transformation of Medicine and Its Impact on Costs and Access to Care
}

\author{
John P. Geyman, MD
}

In 1980, Arnold Relman, former Editor of The New England Fournal of Medicine, noted the emergence of the medical- industrial complex, a huge new forprofit industry ranging from proprietary hospitals and nursing homes to diagnostic services, medical devices, hemodialysis, the pharmaceutical industry, the insurance industry, home care, and many other related proprietary activities. He issued this warning 23 years ago:

This new "medical-industrial complex" may be more efficient than its nonprofit competition, but it creates the problems of overuse and fragmentation of services, overemphasis on technology, and "cream-skimming," and it may also exercise undue influence on national health policy. Closer attention from the public and the profession, and careful study are necessary to ensure that the "medical-industrial complex" puts the interests of the public before those of its stockholders. ${ }^{1}$

This article has 3 main goals: (1) to examine the extent of corporate transformation within the medical-industrial complex today; (2) to assess the impact of these changes on health care costs and primary health care access; and (3) to offer some suggestions for more effective cost containment as a means to make health care more affordable and to improve access to care.

Submitted, revised 16 April 2003.

From the Department of Family Medicine, University of Washington, Seattle. Address reprint requests to John P. Geyman, MD, Department of Family Medicine, University of Washington, Box 354696, Seattle, WA 98195 (e-mail: jgeyman@u.washington.edu).

Presented at the Fourteenth National Conference on Primary Health Care Access; 2003 Apr 11; Kauai, Hawaii.

\section{Extent of Corporate Transformation}

The corporatization of American medicine has extended into all parts of the health care system, including expansion into the public sector (eg, forprofit mental health programs under state Medicaid contracts.) $)^{2}$ Increasingly, Wall Street and the interests of shareholders have replaced Main Street in shaping the organization of health care, the market, and even clinical decisions. The following demonstrates how far this "quiet revolution" has gone.

\section{Hospital Chains}

The advent of investor-owned, for-profit hospital chains started in the 1960s and gathered momentum in a largely unregulated open market fueled by private and public payers and tax policies favoring growth. Although they account for only about $15 \%$ of U.S. hospitals today, their influence far exceeds these numbers. The largest hospital chain todayHCA—owns 181 hospitals and 80 outpatient surgery centers in the United States, England, and Switzerland. ${ }^{3}$ The second largest hospital chain, Tenet (formerly National Medical Enterprises), owns 114 acute care hospitals in 16 states.

A 2003 report by the Committee on the Consequences of Uninsurance of the Institute of Medicine found persuasive evidence that for-profit hospitals set their rates to maximize profits. ${ }^{4-7}$ Many proprietary hospitals seek out profitable markets and abandon unprofitable ones without regard to community needs. The focus of investor-owned hospital chains is frequently on market dominance whereby they can establish favorable reimbursement rates. Typically, they enter a local market, buy up hospitals to get at least a $40 \%$ market share, then close the least profitable hospitals while maintaining market share and transferring the care of the uninsured or underinsured to the public sector. ${ }^{8-10}$ As examples of this trend, HCA and Tenet now control almost $80 \%$ of hospital beds in $\mathrm{El}$ 
Paso, Texas. ${ }^{3}$ In communities in which investorowned hospitals dominate the market, Medicare pays more, not just for hospital care, but for care in other facilities and at home as well. ${ }^{11}$

For-profit hospitals have been shown by various studies to be $3 \%$ to $11 \%$ more costly than not-forprofit hospitals; no peer-reviewed study has yet found them to be less expensive. ${ }^{12,13}$ They invariably spend more on administration and other ancillary services and spend less on nursing staff and other clinical staff. A 1997 national study of 5201 acute care hospitals found that wage and salary costs of clinical personnel in for-profit hospitals was $40.9 \%$ of their total costs, compared with $48 \%$ at not-for-profit and public hospitals. ${ }^{14}$

Despite their inflated rates, for-profit hospitals have been shown by many studies to provide worse quality of care, in large part because of cutbacks in nursing staff. ${ }^{15-18}$ Two examples represent these differences. In a national 1999 study, death rates for seriously ill Medicare patients were $7 \%$ higher in for-profit hospitals compared with not-for-profit nonteaching hospitals and $25 \%$ higher than notfor-profit or government teaching hospitals. ${ }^{16}$ In another study of 16.9 million Medicare patients reported in 2000 , mortality rates for surgical patients were $13 \%$ higher in for-profit hospitals compared with their not-for-profit counterparts. ${ }^{17}$

Here are some ways in which for-profit hospital chains leverage their influence beyond ownership of hospitals:

- ownership and management of laboratories, rehabilitation, long-term care, and psychiatric services. $^{19}$

- asserting their political and financial clout in rate setting against insurers and managed care organizations.

- setting up their own financing mechanisms by ownership of health insurance plans. ${ }^{20}$

- lobbying legislators and regulators at state and federal levels for favorable treatment of their corporate interests.

The unrestrained growth of investor-owned hospital chains has more to do with corporate selfinterest than the public interest, as shown by these examples:
- For profit hospitals are less likely than not-forprofit hospitals to provide care for the uninsured. $^{21}$

- Not-for-profit hospitals that convert to for-profit status provide much less uncompensated care after conversion..$^{22,23}$

- During the recession of 2001, increased profits for the third quarter of $47 \%$ and $45 \%$ were reported by HCA and Tenet, respectively. ${ }^{25}$

- In California, Tenet's hospitals charged an average of 10 times the cost of drugs; one of its hospitals charged 18 times their cost. ${ }^{26}$

- Rampant fraud in billing practices [eg, HCA, after being fined $\$ 840$ million in 2001 for Medicare fraud, agreed to pay the U.S. government another \$631 million to resolve other fraud allegations (overcharged Medicare cost reports and kickbacks to physicians for referrals to HCA hospitals)]. ${ }^{27}$

- Profiteering by hospital chain CEOs (eg, Tenet's CEO cashed in \$111 million in stock in January 2002, soon after reporting grossly inflated company earnings; the company was rocked by scandal and its stock dropped $70 \%$ in 2002). ${ }^{28}$

\section{HMOs}

About two-thirds of HMOs are for-profit corporate organizations. For-profit HMOs are typically driven by the market with a strong focus on managing costs rather than care. This is in marked contrast to not-for-profit HMOs, such as Kaiser Permanente and Group Health Cooperative of Puget Sound, with their more socially oriented emphasis on prevention, patient education, and cost-effective, evidence-based care. Proprietary HMOs attempt to "cherry pick" the market; avoid sicker enrollees; erect barriers to specialist referral, costly diagnostic tests, and hospitalization; and divest themselves of high-utilizing physicians who order too many tests or spend too much time with patients. ${ }^{29}$ Compared with not-for-profit HMOs, for-profit HMOs have been documented to have higher disenrollment rates ${ }^{30}$ lower patient satisfaction, ${ }^{31}$ and worse quality of care. ${ }^{32,33}$ For example, a national study of investor-owned HMOs in 1999 found that they scored worse on all 14 quality indicators than not-for-profit plans. ${ }^{32}$

For-profit HMOs aggressively sought out profits over care during the managed-care era of the 1980s and 1990s. While charging high overhead for administration and profits (25 to $33 \%$ for some of 
the largest HMOs), ${ }^{34}$ their everyday denials of care led to a public and legal revolt against their abuses. ${ }^{29,35-38}$ Instead of their claimed benefits of increased competition in the marketplace, consolidation of fewer, larger HMOs led to oligopoly with reduced competition. ${ }^{34}$ The controversial role of the primary care gatekeeper became discredited, and barriers to specialist care were lowered under public pressure. The trade-off, of course, was higher premiums to enrollees, increased disenrollment rates, and interruptions in continuity of care for many patients.

These examples reflect typical behavior of forprofit HMOs counter to the public interest:

- many for-profit HMOs manipulate or withdraw from voluntary national monitoring systems of quality of care; poor quality HMOs are more than 3 times more likely to stop reporting data to the National Committee for Quality Assurance. $^{39}$

- Denials by HMOs of medical necessity are frequently arbitrary and capricious; ${ }^{40}$ when challenged legally, they go to some length to avoid legal and ethical accountability. ${ }^{41}$

- Well Point Health Networks of California (the parent of the for-profit Blue Cross of California) "leads" most for-profit HMOs in the "medical loss ratio" (ie, the cost of providing care divided by premiums collected) at just under $81 \% .^{42}$

- Profiteering by executives of for-profit HMOs (eg, in 2000, 23 top executives of investor-owned HMOs were paid more than $\$ 63$ million in salary plus $\$ 109$ million in stock options). ${ }^{25, \mathrm{p} 8}$

The practices of investor-owned HMOs also impact the public sector as well as the not-for-profit, more socially responsible HMOs:

- After reaping short-term profits, many Medicare Plan Choice HMOs have abandoned the Medicare market, forcing more than 600,000 enrollees to find other coverage; ${ }^{43}$ those remaining in the market in 2003 typically increase premiums and reduce benefits. ${ }^{44}$

- A Missouri jury recently awarded a group of pediatricians with an inner-city, largely Medicaid practice more than \$6 million; they filed suit against Blue Cross and Blue Shield of Kansas City, their Medicaid HMO, for failure to honor their capitation contract. The KC Blues had dipped into their not-for-profit HMO's funds to create a replacement for-profit Medicaid HMO, even soliciting enrollees to shift from the nonprofit HMO to the for-profit one. ${ }^{45}$

- Nonprofit HMOs, such as Kaiser Permanente, are now facing adverse selection within its aging population as for-profit HMOs continue to "cherry pick" the market by offering lower cost plans with more limited benefits to healthier enrollees. ${ }^{46}$

\section{Insurance Industry}

Most of the country's health insurers are for-profit and many are investor-owned. ${ }^{47}$ The health insurance industry has followed the same trend we have seen among hospitals and HMOs-mergers, consolidation, and oligopoly. Large national insurers (eg, Aetna, United Health Group, and Cigna) dominate the group market, whereas Blue Cross-Blue Shield (BCBS) plans dominate the individual market. ${ }^{47}$ The original concept of socially responsive health insurance, as pioneered by Blue Cross in the 1930s with community rating (ie, same coverage and premiums for enrollees throughout the covered community, regardless of individual risk), has long since given way to an actuarial model of health insurance whereby premiums are based on enrollees' individual risks. Almost half of the nation's BCBS plans are now for-profit. ${ }^{48}$ Most health insurers now practice "medical underwriting," whereby premiums are reassessed on a regular basis, with big increases or disenrollment if covered persons or groups get sick. Before the 1970s, that practice was considered unethical. ${ }^{49}$ Risk rating allows insurers to avoid coverage of the sick and maximize profits, thereby voiding the basic concept of insurance to spread infrequent large losses over a wide base. ${ }^{47}$ It allows insurers to avoid coverage of higher-risk groups and persons, transferring their care to not-for-profit providers and the public sector.

In the aftermath of the backlash to managed care, hospitals, HMOs and providers continue to battle insurers for higher reimbursements as insurers continue to hike premiums and pass along the increased costs to employers and consumers. Health insurers are still experiencing double-digit profit growth, and a recent Goldman Sachs release expects that trend to increase over the next 2 years. ${ }^{50}$ That for-profit versus not-for-profit makes a big difference is shown by this recent finding: in 


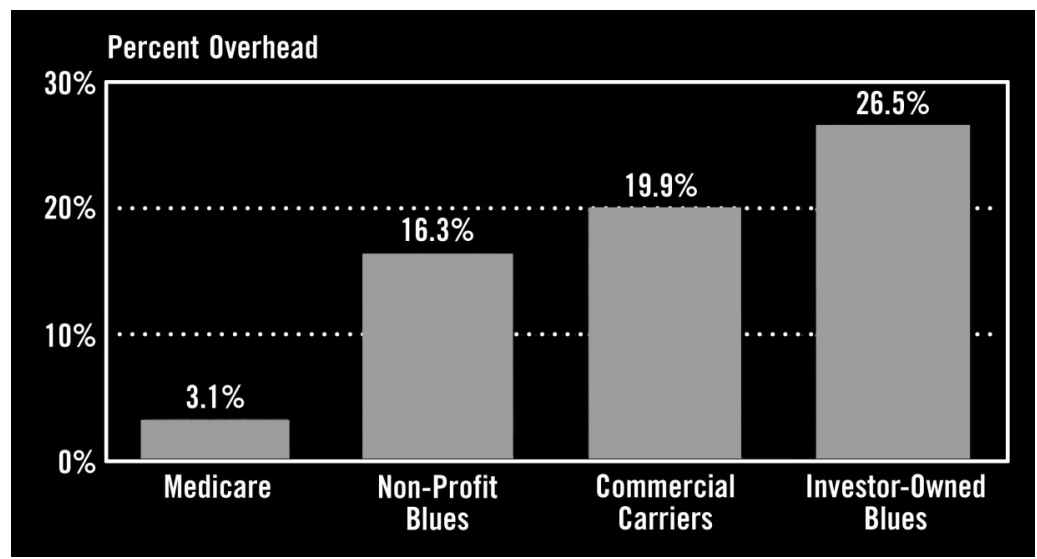

Figure 1. Private insurer's high overhead. Investor-owned plans are worst. Source: Schramm, Blue Cross conversion, Abell Foundation, and CMS.

California, the 2 largest health insurers are Kaiser Permanente (not for profit) and Blue Cross (for profit); in 2000, Kaiser spent $96 \%$ of every premium dollar on medical care, whereas Blue Cross spent just $76 \%$ on medical care. ${ }^{51}$ Figure 1 shows the market increase in overhead costs charged by investor-owned insurance plans compared with Medicare and not-for-profit Blues.

Here are some examples of practices within the health insurance industry that raise concerns about their effects on costs and access to health care.

- American Medical Security (the name belies its practices) illustrates how a health insurer, through reunderwriting, can lower its loss ratio, decrease its enrollees, and still increase its profits. ${ }^{52}$

- Faced with an unprofitable loss ratio for an entire group, Mid-South Health Plan canceled coverage for the entire group of 100,000 people (sick persons often found alternative coverage either unaffordable or unavailable). ${ }^{53}$

- Insurers frequently avoid state insurance regulations, which may disallow premium rate increases, by setting up administrative offices in states with lax regulations. ${ }^{54}$

- For-profit health insurers often set up nonprofit associations, claimed to be independent, to sell insurance policies as allegedly better deals, as a front for the for-profit insurers. ${ }^{55}$

- EHealth Insurance, in partnership with 135 insurance carriers, takes a 20\% broker's fee for any health insurance policy sold over the Internet, plus another $10 \%$ fee for any policy holders who renew their coverage, whether or not through Ehealth. $^{56}$

- Many large health insurers use one or another software programs made by McKesson Corporation of San Francisco to automatically limit reimbursements to more than 600,000 U.S. physicians. ${ }^{57}$

- In the last 10 years, the federal government has recovered more than $\$ 400$ million in settlements from health insurance companies making false Medicare claims. ${ }^{58}$

- Profiteering is widespread throughout the investor-owned health insurance industry (eg, Aetna's CEO received $\$ 16$ million in total compensation for only 4 months' work). ${ }^{59}$

\section{Pharmaceutical Industry}

The investor-owned pharmaceutical industry leads all other industries in the United States in terms of profits. In 2001, during a time of recession, the top 10 U.S. drug companies increased their profits by $33 \%$, whereas the overall profits of Fortune 500 companies declined by $53 \% .{ }^{60}$ The industry argues that its prices are necessary for innovation and development of new drugs, but the evidence is overwhelming that unrestrained profiteering has been the rule for many years. The industry was investigated more than 40 years ago by the Kefauver committee, which reported in 1960 that drug companies spent 4 times as much on promotion than on research. ${ }^{61}$ Public Citizen estimates that the drug industry today makes $17 \%$ of revenues in profits and spends $15 \%$ on marketing and $6 \%$ on research. $^{62}$ According to Securities Exchange 
Commission (SEC) reports for 2001, the big drug companies spent about $35 \%$ of revenues on marketing. ${ }^{63}$

The prices of pharmaceuticals are unregulated in this country, allowing continued inflated pricing in the United States in marked contrast to other countries around the world, where drug prices are regulated by governments. As a result, many millions of people can no longer afford essential drug treatments, including those covered by such public sector programs as Medicare and Medicaid. Yet the industry maintains a primary focus on profits with little regard for the public interest. It pursues a sophisticated set of strategies that in large part control the research, development, marketing, and even regulation of drug products while effectively lobbying legislators to avoid price controls. These are just a few examples:

- The free market for prescription drugs around the world averages only one quarter of the U.S. monopoly price. ${ }^{64}$

- Gaming patent laws to extend their patents by various ploys, including filing for new patents for "new" uses of old drugs, filing a "citizen petition" to oppose generic competition, and filing frivolous lawsuits against competitors. ${ }^{65}$

- Contracting with a competing drug company not to market a cheaper generic drug. ${ }^{66}$

- Battling against imports of prescription drugs into the United States from Canada by such methods as advertising campaigns questioning the safety and effectiveness of generic drugs ${ }^{67}$ and requiring Canadian pharmacies to "self-certify" that they are not exporting drugs outside Canada or have their supplies cut off. ${ }^{68}$

- Promoting expensive "me too" drugs as a "breakthrough" when they have not been shown to be more effective than older drugs (eg, Nexium promotion as Prilosec went generic). ${ }^{69}$

- Compromised integrity of drug research whereby research methods, analysis, and reporting of data are often controlled by the drug companies themselves, which fund contract research organizations in private practice settings (now more than 1000 CROs worldwide) as well as considerable drug research in academic centers. ${ }^{63}$

- Suppression of research results that are unfavorable to their drugs (eg, \$135 million settlement by Knoll Pharmaceuticals for blocking negative research findings for 7 years $)^{70}$ and pressures brought against a principal investigator, dean, and a journal editor to block publication of unfavorable results. ${ }^{71}$

- Attempts to create a market by medicalizing or inventing a new disease (eg, "female sexual dysfunction," which has been "defined" as an allegedly common problem affecting $43 \%$ of women through flawed "research" involving consensus development conferences fully funded by the drug industry). ${ }^{72,73}$

- Devious direct-to-consumer advertising, with persistent violations of FDA regulations, ${ }^{74}$ even including illegal advertising for off-label uses of drugs (eg, Neurontin for bipolar disorder, attention deficit disorder, and migraines). ${ }^{75}$

- Conflict of interest in regulatory process by FDA, whereby the FDA is dependent on "user fees" by the pharmaceutical industry for half of its funding; this arrangement was enacted by Congress in 1992, renewed in 2002, and coincides with faster approvals of drugs and a 4-fold increase in drug withdrawals from the market for safety reasons. ${ }^{76}$

- Outright fraud (eg, overcharging Medicare \$1.9 billion in 2001 for 24 common prescription drugs). ${ }^{77}$

- Runaway levels of CEO compensation (eg, \$74.9 million in 2002 for BristolMyers-Squibb CEO and more than $\$ 93$ million in stock options for Merck CEO). ${ }^{78}$

\section{Medically Related Industries}

There are many medically related industries within the overall medical-industrial complex, generally for-profit and many investor-owned. Three examples suggest the scope of these industries as well as the profit-driven mission of each.

\section{Mental Health Facilities}

More than $80 \%$ of managed mental health firms are for-profit. ${ }^{79}$ Mostly investor-owned, a large managed mental health care industry has developed over recent years with a poor record of service and a consistent record of blatant profiteering. In 2000, the 10 largest firms covered more than 140 million Americans, mostly through subcontracts with HMOs. These firms typically limit care by excluding skilled therapists providing "excessive" care and by restrictive utilization review (eg, requiring delirium tremens before a hospital admission for detoxification). A 1998 audit by the Congressional 


\section{Average Cost Increases: 1993-2003}

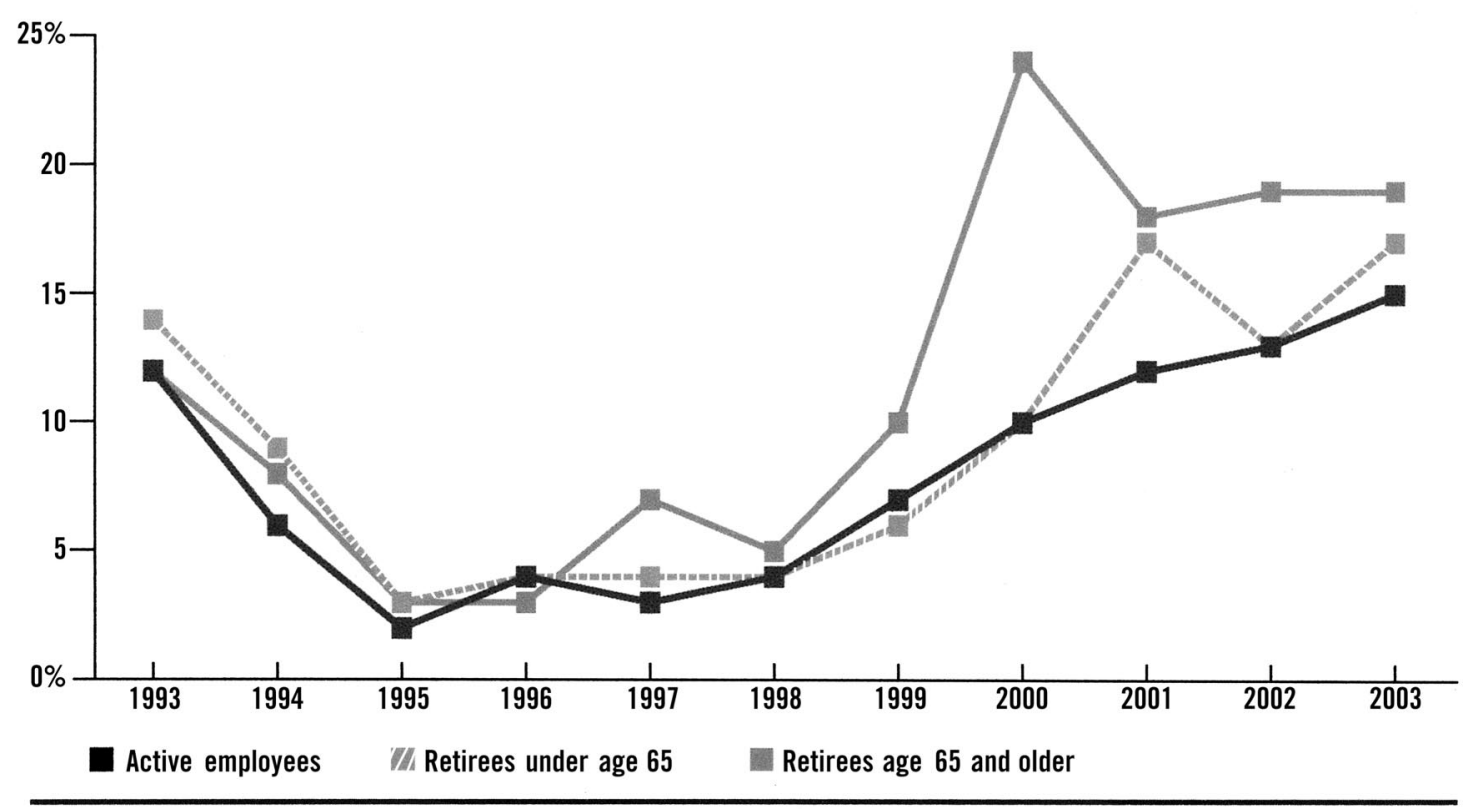

Figure 2. Average cost increases, 1992-2003.

Budget Office revealed examples of poor performance and profiteering-quality problem in 30\% of cases reviewed, overstated utilization by $45 \%$, no provider in $15 \%$ of counties "covered," overhead and profit consistently more than $45 \%$ of premiums. ${ }^{80}$

\section{Dialysis Centers}

Eighty-five percent of dialysis centers in the US are for-profit, and they compare poorly with their not-for-profit counterparts-death rates are 30\% higher with $26 \%$ less use of transplants in 1 study reported in $1999 .{ }^{81} \mathrm{~A}$ more recent systematic review and meta-analysis estimated that there are 2500 excessive premature deaths each year in US for-profit dialysis centers. ${ }^{82}$ Emphasis on bottomline profits leads to cutbacks of staff and the use of shorter dialysis periods (average of 10 hours per week in the United States compared with 12 in Germany and 14 in Japan). ${ }^{12, p p 137-8}$ Frensenius Medical Care North America (a German firm) is the largest provider of kidney dialysis products in the world, with more than 800 dialysis facilities in the US. After pleading guilty to charges of conspiracy and fraud, it paid \$486 million in fines and settlements to the government in $2000 .^{83}$

\section{Nursing Homes}

Seventy percent of nursing homes are for-profit, again including many under corporate ownership. A 1998 study by the General Accounting Office in California found that $30 \%$ of facilities had committed violations that caused "death or life-threatening harm to patients." 84 Experts have agreed that 4.5 hours of nursing care are required each day to provide safe and adequate care to nursing home patients. Only 1 state (Alaska) meets that level, with some states as low as 3 hours per day. ${ }^{85}$ Medicaid and Medicare pay for about two thirds of the costs of nursing home care, and cutbacks in reimbursement in these programs have hit nursing homes hard. Yet, as with hospital, HMOs, and drug companies, fraud remains part of the problem. A large corporate chain of nursing homes, Beverly Enterprises, settled for $\$ 175$ million in Medicare fraud in $2000 .{ }^{86}$

\section{Impact of Corporatization on Costs and Access}

The foregoing shows that Relman's concerns of 23 years ago have largely come to pass. The corporatization of health care has become a dominant force in the US and is a powerful driver of increased health care costs. Figure 2 shows the dramatic in- 


\begin{tabular}{ll}
\hline Hospitals & $\begin{array}{c}\text { Costs } 3 \% \text { to } 13 \% \text { higher, with higher overhead, fewer nurses, and death rates } 6 \% \text { to } 13 \% \\
\text { higher. }{ }^{11,17,88}\end{array}$ \\
HMOs & $\begin{array}{c}\text { Higher overhead (25\% to } 33 \% \text { for some of the largest HMOs), worse scores on } 14 \text { of } 14 \text { quality } \\
\text { indicators reported to National Committee for Quality Assurance }{ }^{32,33}\end{array}$ \\
Death rates $30 \%$ higher, with $26 \%$ less use of transplants & 81,82 \\
Dialysis centers & $\begin{array}{c}\text { More citations for poor quality of care (30\% committed violations which caused death or life- } \\
\text { threatening harm to patients) }\end{array}$ \\
Nursing homes & Medicare expelled 80 programs after investigations found that $91 \%$ of claims were fraudulent \\
Mental health centers &
\end{tabular}

crease in recent years of health care costs for retirees and active employees. Admittedly, health care inflation is complex and is also driven by other important factors, such as technological progress, aging of the population, and consumer demand. However, the extent of profiteering in a largely unregulated health care marketplace stands out as a major, and probably underestimated, impediment to cost containment.

Our experiment with market-based medicine, going back 30-plus years, has been a failure, except in enriching the corporate stakeholders. Two examples illustrate the point. On the state level, Minnesota's experience with managed care documented increasing costs to enrollees as well as increases in the numbers of uninsured and enrollees in public programs. ${ }^{89}$ At the national level, the claimed advantages of the competitive private market in achieving lower costs and higher efficiency quickly evaporated in recent years as Medicare+Choice HMOs abandoned the Medicare market in droves. $^{43,44}$

It would be one thing if investor-owned, corporate health care brought increased efficiency and value to the market, but just the opposite is the case. Instead, for example, the huge for-profit health insurance industry takes one quarter of the health care dollar while separating the relatively healthy from the sick and fragmenting the risk pool. ${ }^{90}$ For-profit plans and facilities are consistently found to have lower quality of care than their not-for-profit counterparts, whether $\mathrm{HMOs}^{32}$ hospitals, ${ }^{15-18}$ dialysis centers, ${ }^{81,82}$ or nursing homes. ${ }^{86}$ Table 1 summarizes some of the evidence documenting increased costs and lower quality of care in investor-owned facilities.

In addition to being more expensive with less quality of care compared with not-for-profit facilities, investor-owned corporate health care returns fewer benefits to the community. Private not-for- profit and public facilities are forced to take on an even larger responsibility for such community benefits as care of the uninsured, Medicaid beneficiaries, and patients requiring care on trauma services and burn units. ${ }^{4}$

Health care has become unaffordable, not just for lower-income people, but for a growing part of the middle class as well. Today, there is clearly a "medical divide" by income at roughly $\$ 50,000$ per year (Figure 3). Almost 14\% of Americans earning less than that income (which is about $300 \%$ of federal poverty levels) have no health insurance, mostly for reasons of unaffordability. ${ }^{90}$ That group represents balf of the nonelderly population in the US $^{91}$ This "medical divide" will only get worse as health care costs continue to escalate. Employers have experienced premium increases of $15 \%$ in 2002 with projections for a $23 \%$ increase in $2003 .{ }^{92}$ They are passing along these costs to employees, with a growing number of workers no longer being able to afford coverage. Meanwhile, the average annual per capita cost of health care has reached $\$ 5700$, and government is paying about $60 \%$ of the total costs of a wasteful, inefficient, and unfair system. ${ }^{93}$

As health care has become more unaffordable for an increasing part of the population, these hard facts stand out about decreasing access to care:

- More than 41 million Americans (about 1 in 7), including 8 million children, have no health insurance over an entire year. $^{94}$

- $80 \%$ of the uninsured live in working families. ${ }^{95}$

- $20 \%$ of workers cannot afford health insurance even when offered by their employers. ${ }^{96}$

- More than one third of workers who lose their jobs are unable to regain health insurance, and an equal number of applicants in the individual insurance markets are turned down. ${ }^{25, \mathrm{pp}^{4-5}}$ 


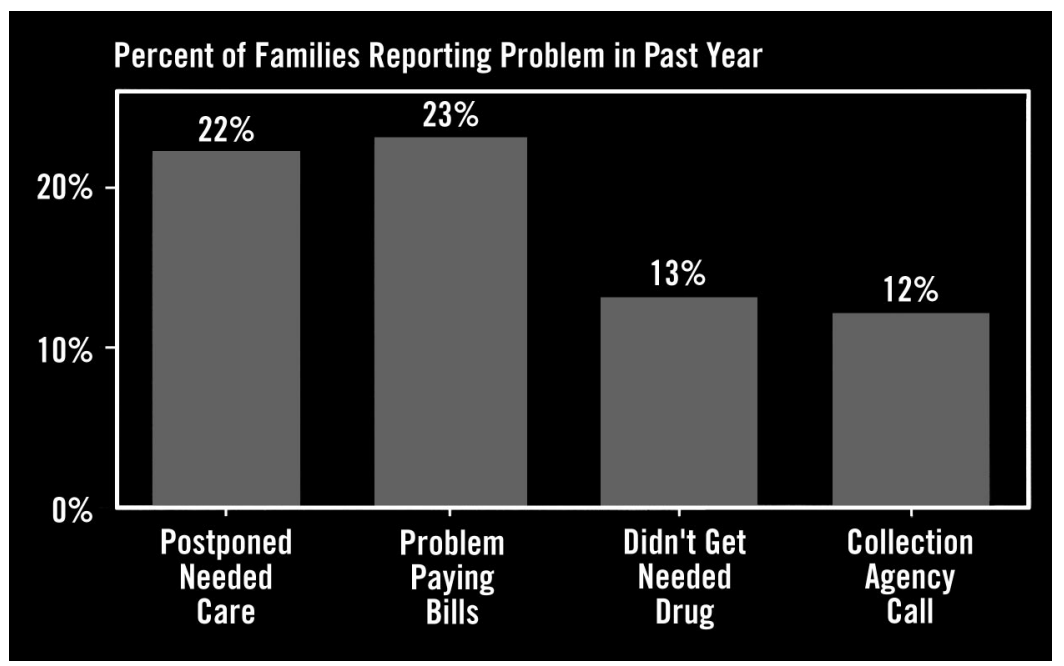

Figure 3. Access problems for middle class families (income \$25,000-49,999). "Problems Paying Bills" and "Collection Agency Calls" refer only to medical bills. Source: NPR/Kaiser survey, June 2002.

- There are growing disparities of health care by income, class, and ethnicity that increasingly threaten the middle class. ${ }^{97}$

Insurance coverage, whether private or public, has been found to be the single most important factor for adequate access to care. The uninsured are much less likely to have a usual source of primary care. There are serious outcomes from the lack of primary care, including delays in seeking care; inability to afford medications, higher rates of preventable hospitalizations, complications, and death; and declines in health or functional status. ${ }^{88-100}$

The problems of unaffordability and decreased access to health care extend beyond the uninsured to include a large segment of the population that is underinsured, including many millions with public sector coverage. For example, 40 million Medicare recipients are without public coverage for prescription drugs, and more than one quarter of Medicaid enrollees cannot afford drug prescriptions. ${ }^{101}$ With the country continuing in a period of economic slowdown and with serious budget deficits at both the federal and state levels, these problems are certain to become worse in the near future. Public safety net programs are already seriously underfunded. Facing cutbacks in reimbursement rates, which often do not cover practice overhead, one third of U.S. physicians will no longer see a new Medicare patient. ${ }^{102}$ To make matters worse, a protracted recession is projected to increase the number of uninsured and Medicaid beneficiaries by $75 \%$ each by $2007 .^{103}$

\section{Discussion}

The medical-industrial complex, with all its disturbing elements, has become fully entrenched at the core of the U.S. health care system. The costs of this revolution, in terms of dollars, inefficiency, and decreased value, are only now starting to become clear. For investor-owned health care corporations, money is the mission, not the public interest. The flaws of an unregulated market system have been exposed; unfortunately, there is still insufficient public and professional awareness of the gravity of these problems. There is also no end in sight to spiraling inflation of health care costs. The latest estimate by the Centers for Medicare and Medicaid Services projects U.S. health care spending to more than double to $\$ 3.1$ trillion $(17.7 \%$ of GDP) in 2012. ${ }^{104}$ Nevertheless, our legislators still argue for pro-market incremental changes without regard to their effectiveness, while corporate stakeholders of the status quo maintain a near-stranglehold on fundamental reform through their campaign contributions to both parties and lobbying activities with the government and the media. ${ }^{105}$

Given today's increasing problems in our health care system, what can we do now as physicians and educators? Here are some suggestions: 
- Recognize the big picture of a failing health care system pricing itself beyond the reach of a large and increasing part of the population.

- Accept the need for fundamental system reform, especially the urgent need for some form of social health insurance, whether state-by-state or nationally, whereby cost savings can be achieved by eliminating waste and duplication of services, more efficient administration, and the increased bargaining power of large purchasers on a notfor-profit basis.

- Question the value of proposed incremental changes based on their previous track record and whose interests they serve.

- Recognize the practices and defenses of investorowned health care corporations for what they are, including their corruptive influence on government and the media.

- Track access to care within your own community and state.

- Advocate for disadvantaged individuals and groups through patient care, teaching, and role modeling the best traditions of public service.

- Incorporate system and ethical issues into teaching programs for medical students, residents, and practicing physicians.

- Become more involved with education of the public concerning solutions to problems of the health care system.

- Take a leadership role in grassroots health care reform, including participation in such organizations as Citizens Action groups and Physicians for a National Health Program (PNHP).

Organized medicine has often been on the wrong side of history, for the wrong reasons (eg, the AMA's battle against Medicare and Medicaid during the 1960s). As our market-based system flounders and falls apart early in the 21 st century, we have the opportunity to be on the right side of history for the right reasons.

\section{References}

1. Relman AS. The new medical-industrial complex. N Engl J Med 1980;303:963-70.

2. Munoz R. How health care insurers avoid treating mental illness. San Diego Union Tribune 2002 May 22.

3. Stein L. Pulling the plug. Metro. Silicon Valley's Weekly Newspaper 2002 Sep 20. Available at: URL: http://www.metroactive.com/papers/metro/ 09.19.02/hospital-0238.html.
4. Committee on the Consequences of Uninsurance, Institute of Medicine. Shared destiny: community effects of uninsurance. Washington, DC: The National Academy Press, 2003:51.

5. Hoerger TJ. "Profit" variability in for-profit and not-for-profit hospitals. J Health Econ 1991;10: 259-89.

6. Needleman J. For-profit conversions. Nonprofit to for-profit conversions by hospitals, health insurers, and health plans. Public Health Rep 1999;114: 108-19.

7. Zwanziger J, Melnick GA, Bamezai A. Can cost shifting continue in a price competitive environment? Health Econ 2000;9:211-26.

8. Coye MJ. The sale of Good Samaritan: a view from the trenches. Health Aff (Millwood) 1997;16: 102-7.

9. Martinez B. After an era of dominant HMOs, hospitals are turning the tables. Wall Street Journal 2002 Apr 12. Available at: URL: http://www.legacyalliance. net/Articles/News/HospitalsTurningTables.htm.

10. White RD. Tenet continuing resurgence. The Los Angeles Times. 2002 Jan 5.

11. Silverman EM, Skinner JS, Fisher ES. The association between for-profit hospital ownership and increased Medicare spending. N Engl J Med 1999; 341:420-6.

12. Himmelstein DU, Woolhandler S, Hellander I. Bleeding the patient: the consequences of corporate healthcare. Monroe, ME: Common Courage Press, 2001:127-8.

13. Kuttner R. Columbia/HCA and the resurgence of the for-profit hospital business. N Engl J Med 1999;335:446-51.

14. Woolhandler S, Himmelstein DU. Costs of care and administration at for-profit and other hospitals in the United States. N Engl J Med 1997;336: 769-74.

15. Hartz AJ, Krakauer H, Kuhn EM, et al. Hospital characteristics and mortality rates. $\mathrm{N}$ Engl J Med 1989;321:1720-5.

16. Chen J, Radford MJ, Wang Y, Marciniak TA, Krumholz HM. Do "America's Best Hospitals" perform better for acute myocardial infarction? N Engl J Med 1999;340:286-92.

17. Yuan Z, Cooper GS, Einstadter D, Cebul RD, Rimm AA. The association between hospital type and mortality and length of stay: a study of 16.9 million hospitalized Medicare beneficiaries. Med Care 2000;38:231-45.

18. Kovner C, Gergen PJ. Nurse staffing levels and adverse events following surgery in U.S. hospitals. Image J Nurs Sch 1998;30:315-21.

19. 1998 Environmental assessment: setting foundations for the new millennium, survey. Irving, TX: VHA, Inc.; 1998.

20. Kirchner M. Will you have to join a hospital chain to survive? Med Econ 1985;62:164-76. 
21. Mann JM, Melnick GA, Bamezai A, Zwanziger J. A profile of uncompensated hospital care, 1983-1995. Health Aff (Millwood) 1997;16:223-32.

22. Needleman J, Lamphere J, Chollet D. Uncompensated care and hospital conversions in Florida. Health Aff (Millwood) 1999;18:125-33.

23. Desai KR, Lukas CV, Young GJ. Public hospitals: privatization and uncompensated care. Health Aff (Millwood) 2000;19:167-72.

24. Deleted in proof.

25. Data update. PNHP Newsletter. 2002 Jan:7.

26. Abelson R. Nurses' Association says in study that big hospital chain overcharges patients for drugs. The New York Times 2002 Nov 24; Sect. 1:26.

27. Martinez B. HCA accusers may challenge U.S. settlement. The Wall Street Journal 2002 Dec 19; Sect. A:5.

28. Data update. PNHP Newsletter. Spring 2003:10.

29. Kuttner R. Must good HMOs go bad? First of two parts: the commercialism of prepaid group health care. N Engl J Med 1998;338:1558-63.

30. Comparing Medicare HMOs. Do they keep their members? Washington, DC: Families USA, 1997.

31. When things go wrong. Consumer Reports 1996; 62(8):39-42.

32. Himmelstein DU, Woolhandler S, Hellander I, Wolfe SM. Quality of care in investor-owned vs not-for-profit HMOs. JAMA 1999;282:159-63.

33. The HMO honor roll. U.S. News \& World Report 1997 Oct 23:62.

34. Kuttner R. The American health care system: Wall Street and health care. N Engl J Med 1999;340: 664-8.

35. Duff C. Americans tell government to stay outexcept in case of health care. The Wall Street Journal 1998 Jun 25; Sect. A:9,14.

36. Pollitz K, Crowley J, Lucia K, Bangit E. Assessing state external review programs and the effects of pending Federal patients' rights legislation. Menlo Park, CA: Henry J. Kaiser Family Foundation, 2002.

37. Rush Prudential HMO Inc v Moran (00-1021), 230 F3d 959, affirmed. Available at: URL: http://www. supremecourtus.gov/opinions/01pdf/00-1021.pdf

38. Rice B. When an HMO denial is practicing medicine. Med Econ 2002;79:100, 103, 107.

39. McCormick D, Himmelstein DU, Woolhandler S, Wolfe SM, Bor DH. Relationship between low quality-of-care scores and HMOs subsequent public disclosure of quality-of-care scores. JAMA 2002; 288:1484-90.

40. Court J, Smith F. Making a killing: HMOs and the threat to your health. Monroe, ME: Common Courage Press, 1999.

41. Peeno L. HMOs seek whitewash instead of facing misdeeds. The Wall Street Journal 2002 Jul 26; Sect. A:11.
42. Lee D. A bright spot in health insurance. The Los Angeles Times 2002 Apr 25; Sect. C:1.

43. Waldholz M. Prescriptions. Medicare seniors face confusion as HMOs bail out of program. The Wall Street Journal 2002 Oct 3; Sect. D:4.

44. Barry P. More HMOs leave Medicare. AARP Bulletin 2002 Nov;43:1.

45. Lowes R. We nailed an HMO for \$6 million. Med Econ 2002;79(24):60-2, 65-7.

46. Lee D. Rising costs put pressure on Kaiser. The Los Angeles Times 2002 Sep 29.

47. Competition in the markets. On Managed Care 2001 Apr;6:1.

48. Song KM. Hospitals sue Premera to halt for-profit switch. Seattle Times 2003 Jan 23; Sect. A:1.

49. Kuttner R. Everything for sale: the virtues and limits of markets. Chicago: University of Chicago Press, 1999.

50. News release. FTCR calls for health care rate regulation. Santa Monica, CA: The Foundation for Taxpayer and Consumer Rights, 2002 Oct 4.

51. Benko LB. Managed care. Shakeup in California. Modern Healthcare. 2002 May 13;32.

52. Terhune C. Side effect. Insurer's tactic: if you get sick, the premium rises. The Wall Street Journal 2002 Apr 9; Sect. A:1.

53. Morrison AB, Wolfe SM. Outrage of the month. None of your business. Public Citizen's Health Research Group Health Letter 2001;17(2):11.

54. Terhune C. Insurers avoid state regulations by selling via groups elsewhere. The Wall Street Journal 2002 Apr 9;Sect. A:20.

55. Terhune C. Non-profit groups that tout insurance have hidden links. The Wall Street Journal 2002 Nov 21;Sect. A.

56. Tep R. Click here for coverage. Forbes.com. 2002 Nov 21. Available at: URL: http://www.forbes.com/best/2002/1202/005.html

57. Martinez B. Cigna is stung in ploy to settle rival lawsuits. The Wall Street Journal 2002 Dec 20; Sect. B:1.

58. McGinley L. General American to pay \$76 million in Medicare case. The Wall Street Journal 2002 Jun 26;Sect. A:2.

59. Managed Healthcare Market Report. March 2001: 31.

60. Public Citizen Report. April 18, 2002. Pharmaceutical industry ranks as most profitable industryagain. Public Citizen Report. 2002 Apr 18. Available at: URL: http://www.citizen.org/pressroom/ release.cfm? ID $=1088$.

61. Mintz M. Still hard to swallow. The Washington Post 2001 Feb; Health.

62. Public Citizen Report. 2001 Jul.

63. Relman AS, Angell M. America's other drug problem: how the drug industry distorts medicine and politics. The New Republic 2002 Dec 16;27-41. 
64. Baker D. Patent medicine. The American Prospect 2001 Jan 29:34-5.

65. Editorial. Gaming the patent drug system. The Los Angeles Times 2002 June:10.

66. Ivins M. Drug companies antics can really make you sick. Public Citizen's Health Research Group Health Letter 2001;17(7):4.

67. GPHA rips PhRMA ad. O'Dwyer's PR Services Report 2002 Nov:15.

68. Baglole J. Glaxo tries new tack on cheap Canadian drugs. The Wall Street Journal. 2003 Jan 22;Sect. $\mathrm{D}: 2$.

69. Angell M, Relman AE. Prescription for profit. The Washington Post 2001 Jun 20;Sect. A:27

70. CBS. 60 Minutes. December 1999:r19.

71. Deyo RA, Psaty BM, Simon G, Wagner EH, Omenn GS. The messenger under attack-intimidation of researchers by special-interest groups. N Engl J Med 1997;336:1176-80.

72. Moynihan R. The making of a disease: female sexual dysfunction. BMJ 2003;326:45-7.

73. Chartrand S. Patents: the Viagra counterpart for women is on its way and it addresses a clinical condition new to the popular lexicon. The New York Times 2003 Jan 27;Sect. C:7.

74. Wolfe SM. Direct-to-consumer (DTC) ads: illegal, unethical or both. Public Citizen's Health Research Group Health Letter 2001;17(9):3.

75. Wolfe SM. Update on the illegal promotion of gabapentin (Neurontin). Public Citizen's Health Research Group Health Letter 2002;18(8):3-5.

76. Wolfe SM. Unsafe drugs: congressional silence is deadly (part 2). Public Citizen's Health Research Group Health Letter 2002;18(9):1-4.

77. DHHS. Inspector General report and New York Times. Associated Press Report. September 20;2001.

78. Press release. Families USA. July 2002:17.

79. Kihlstrom LC. Characteristics and growth of managed behavioral health care firms. Health Aff (Millwood) 1997;16:127-30.

80. Wrich J. Brief summary of audit findings of managed behavioral health services. Chicago, IL: J. Wrich \& Associates, Inc., 1998.

81. Garg PP, Frick KD, Diener-West M, Powe NR. Effect of the ownership of dialysis facilities on patients' survival and referral for transplantation. N Engl J Med 1999;341:1653-60.

82. Devereaux PJ, Schunemann HJ, Ravindran N, et al. Comparison of mortality between private for-profit and private not-for-profit hemodialysis centers: a systematic review and meta-analysis. JAMA 2002; 288:2449-57.

83. Press release. Settlement with Fresenius Medical Care. Washington, DC: Office of Inspector General, US Department of Health and Human Services; 2000 Jan 19.
84. Pear R. Government is called lenient toward errant nursing homes. The New York Times. 1998 Jul 27.

85. Wolfe SM. Neglected to death: the scandalous condition of American nursing homes. Public Citizen's Research Group Health Letter 2003;19:1-4.

86. Mod Healthc 2000 Feb 7;30(6).

87. Sullivan K. Strangled competition: a critique of Minnesota's experiment with managed competition. St. Paul, MN: Minnesota COACT and COACT Education Foundation, 1995.

88. Findley S. Research brief. National Institute for Health Care Management Research and Educational Foundation. Med Benefits 2000;17:5-6.

89. Woolhandler S, Himmelstein DU. When money is the mission - the high costs of investor-owned care. N Engl J Med 1999;341:444-6.

90. Appleby J. More high-income Americans go without health insurance. USA Today 2002 Nov 22; Sect. B:1.

91. Health Insurance Coverage in America: 2000 data update. Menlo Park, CA: Kaiser Commission on Medicaid and the Uninsured, 2002:9. Available at: URL: http://www.kff.org/content/2002/4007/ 4007.pdf

92. Data update. PNHP Newsletter. Jan 2002:6.

93. Woolhandler S, Himmelstein DU. Paying for national health insurance-and not getting it. Health Aff (Millwood) 2002;21:88-98.

94. Findley S. Bridge temporary insurance gaps. USA Today 2002 Sep 26;Sect. A:11.

95. Institute of Medicine Report. October 2001:11.

96. Swartz K. Who owns the problem of the uninsured? Inquiry 1996;33:103-5.

97. Committee on the Consequences of Uninsurance. Health insurance is a family matter. Washington, DC: The National Academy Press, 2002:1-10.

98. Hadley J. Sicker and poorer: the consequences of being uninsured. Menlo Park, CA: Kaiser Commission on Medicaid and the uninsured. Kaiser Family Foundation, 2002.

99. Billings J, Minanoviteh T, Blank A. Barriers to care for patients with preventable hospital admissions. New York: United Hospital Fund, 1997.

100. Baker DW, Sudano JJ, Albert JM, Borawski EA, Dor A. Lack of health insurance and decline in overall health in late middle age. $\mathrm{N}$ Engl J Med 2001;345:1106-12.

101. Cunningham PJ. Prescription drug access: not just a Medicare problem. Issue brief no. 51. Washington, DC: Center for Studying Health System Change, 2002. Available at: URL: http://www. hschange.com/CONTENT/429/

102. Wagner L. Citing national losses of $\$ 2.2$ billion, physicians closing doors to seniors. Physician Financial News 2002 May 15;20:1, 24.

103. Institute for the Future. Health and Health Care 
2010: the forecast, the challenges. San Francisco: Jossey-Bass, 2000;123-37.

104. Health spending to double. Practice Trends. Policy \& Practice. Fam Pract News 2003;33:53.

105. Renzulli D. Capitol offenders: how private interests govern our states. Washington, DC: Public Integrity Books, 2002:149-66.

\section{Suggested Reading}

Articles

Grumbach K, Bodenheimer T. Reins or fences: a physician's view of cost containment. Health Aff (Millwood) 1990;9:120-6.

Himmelstein DU, Woolhandler S, Hellander I, Wolfe SM. Quality of care in investor-owned versus not-for-profit HMOs. JAMA 1999;282:159-63.

Pellegrino ED. The commodification of medical and health care: the moral consequences of a paradigm shift from a professional to a market ethic. J Med Philos 1999;24:243-66.

Woolhandler S, Himmelstein DU. When money is the mission-the high costs of investor-owned care. N Engl J Med 1999;341:444-6.

Pellegrino ED. Medical professionalism: can it, should it survive? J Am Board Fam Pract 2000;13:147-9.

Wolfe SM. The destruction of medicine by market forces. Acad Med 2002;77:42.

Books

Bodenheimer TS, Grumbach K. Understanding health policy: a clinical approach. New York: Lange Medical Books/McGraw-Hill, 2002.
Derber C. Corporation nation. Griffin, NY: St. Martin's Press, 1998.

Geyman JP. Health care in America: can our ailing system be healed? Woburn, MA: Butterworth-Heinemann, 2002.

Geyman JP. Falling through the safety net: Americans confront the perils of health insurance. Monroe, ME: Common Courage Press, 2003.

Kuttner R. Everything for sale: the virtues and limits of markets. Chicago: University of Chicago Press, 1999.

Himmelstein DU, Woolhandler S, Hellander I. Bleeding the patient: the consequences of corporate health care. Monroe, ME: Common Courage Press, 2001.

LeBow R. Health care meltdown: confronting the myths and fixing our failing system: Boise, ID: JRI Press, 2002.

Nader R. Crashing the party. New York: St. Martin's Press, 2002.

\section{Newsletters}

Health Letter. Public Citizen Health Research Group, Washington, DC. http://www.citizen.org/hrg/ healthcare/articles.cfm? ID $=6146$

Physicians for a National Health Program. Quarterly newsletter. http://www.pnhp.org/

Other

PNHP Quote of the Day (QoD) http://www. pnhp.org/news/quote_of_the_day.php.

Data updates and reports from Kaiser Commission on Medicaid and the Uninsured, Henry J. Kaiser Family Foundation, http://www.kff.org/sections.cgi?section= kcmu, 1-800-656-4533. 